
.124
$1 \operatorname{lop} T$

\section{Integrated Approach Towards the Application of Horizontal Wells to Improve Waterflooding Performance}

(Contract No. DE-FC22-93BC14951)

\author{
Submitted by \\ The University of Tulsa \\ Tulsa, OK 74104 \\ Principal Investigator : Balmohan G. Kelkar \\ Co-principal Investigators: Chris Liner, Dennis Kerr \\ Contract Date : January 1, 1993 \\ Completion Date : December 31, 1996 \\ Reporting Period : October 1- December 31, 1993
}

\section{Contracting Officer's Representative}

Ms. Rhonda P. Lindsey

U.S. Department of Energy

Bartlesville Project Office

P. O. Box 1398

Bartlesville, OK 74005
Whin

APR 07904

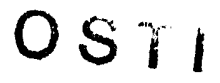

\title{
DISCLAIMER
}

This report was prepared as an account of work sponsored by an agency of the United States Government. Neither the United States Government nor any agency thereof, nor any of their employees. makes any warranty, express or implied, or assumes any legal liability or responsibility for the accuracy, completeness, or usefulness of any information, apparatus, product, or process disclused, or represents that its use would not infringe privately owned rights. Reference herein to any specific commercial product, process, or service by trade name, trademark, manufacturer, or otherwise does not necessarily constitute or imply its endorsement, recommendation, or favoring by the United States Government or any agency thereof. The views and opinions of authors expressed herein do not necessarily state or reflect those of the United States Government or any agency thereof. 


\section{Objectives}

The overall purpose of the proposed project is to improve secondary recovery performance of a marginal oil field through the use of a horizontal injection well. The location and direction of the well will be selected based on the detailed reservoir description using integrated approach. We expect that 2 to $5 \%$ of original oil in place will be recovered using this method. This should extend the life of the reservoir by at least 10 years.

To accomplish the goals of the project, it is divided into two stages. In Stage I, we will select part of the Glenn Pool field (William B. Self Unit), and collect additional reservoir data by conducting cross bore hole tomography surveys and formation micro scanner logs through newly drilled well. In addition, we will also utilize analogous outcrop data. By combining the state of the art data with conventional core and log data, we will develop a detailed reservoir description based on integrated approach. After conducting extensive reservoir simulation studies, we will select a location and direction of a horizontal injection well. The well will be drilled based on optimized design, and the field performance will be monitored for at least six months. If the performance is encouraging, we will enter into second budget period of the project.

If continued, the second budget period of the project will involve selection of part of the same reservoir (Berryhill Unit - Tract 7), development of reservoir description using only conventional data, simulation of flow performance using developed reservoir description, selection of a location and direction of a horizontal injection well, and implementation of the well followed by monitoring of reservoir performance.

By comparing the results of two budget periods, we will be able to evaluate the utility of collecting additional data using state-of the-art technology. In addition, we will also be able to evaluate the application of horizontal wells in improving secondary recovery performance of marginal oil fields.

A successful completion of this project will provide new means of extending the life of marginal oil fields using easily available technology. It will also present a methodology to integrate various qualities and quantities of measured data to develop a detailed reservoir description.

\section{Summary of Technical Progress}

The overall report is divided into three sections. In the first section, we discuss the preliminary results based on the cross bore hole seismic surveys. In the second section, we discuss the geological description of the Self Unit. In the last section, we present petrophysical 
properties description of the reservoir followed by the llow simulation results. Based on a thorough evaluation of the geological and flow simulation results, we finalized the initial test well location followed by drilling of the well in late December. The collected data from the newly drilled well will be evaluated and analyzed in the next report.

\section{Geophysical Data Collection}

A crosswell seismic test was performed in the Self Unit under Upland Resources management (Kiefer, Southeast Creek County) on August 24, 1993. We presented preliminary results on the survey in the last report. 1 This report extends the analysis further.

As a first step, the cross well test intervals were tied to lithological descriptions. This will aid in interpreting specific horizons in the seismic data. Figure 1 shows a detailed explanation of the vertical stacking and source level changes for the experiment. The distance between the net source levels in the survey is identified by symbol D. This distance was $16 \mathrm{ft}$ for fans 1,2 and 3 , and $4 \mathrm{ft}$ for fan 4 . Actually, each net source level is a composite of several actual source levels spaced $2 \mathrm{ft}$ apart. The output from these actual source levels are summed to create a single trace centered on the net source level. This has the effect of supporting random noise.

In the previous report ${ }^{1}$, a display of four test fans were presented. The signal quality was judged to be good to excellent. Based on the data quality and well spacing in our field test (distance of $660 \mathrm{ft}$ ), we are confident that good data quality will be achieved in the full tomography program where well spacing will be $450 \mathrm{ft}$.

The field test did not generate enough data coverage for full tomographic inversion in the image plane between source and receiver wells. However, to test the inversion method, event picking and overlay with lithology, we picked first intervals on all four fans and computed the velocity tomogram shown in Figure 2 . The ray coverage for the shoaling fans is clearly seen in the image. Even with this space coverage, we get a clear early indication of velocity range in the area. We see seismic velocities of $11,000-14,000 \mathrm{ft} / \mathrm{sec}$, with some curious and suspect areas of high velocity. It is important to recall that we have no sonic logs on the Self lease. Thus, the tomogram is our first glimpse at the velocity structure in Glenn Pool.

\section{Geological Description}

Shale maps between reservoir rock (channel-fill and splay sandstones) for each discrete genetic interval (DGI) where constructed in order to assess the potential for vertical connectivity within the Glenn Sand across the 160 acres of the Self Unit. DGI A, B and C appear to be 
vertically separated by non-reservoir rock (floodplain, level, or upper channel-fill mudstones). Only one well (Shelf No. 71) records a zero thickness of nonreservoir rock between DGI B and C. Because the aerial distrivation of DGI $C$ and D are exclusive of each other; however, they may be connected immediately south of the Unit. By contrast, DGI C, E, F and G appear to be vertically connected across much wider areas within the boundaries of the Self Unit.

Natural fractures in the Glenn Sand become a concern to the operator. Therefore, available cores were examined for evidence of natural fractures. No evidence of natural fractures has been identified. However, this issue with also be addressed in core and microresistivity images collected in the vertical test well.

Vertical test well was located to be drilled through DGI A and C net sand isopach closures (DGI B is predicted to be absent by erosion prior to DGI A deposition). A total of 153.2 feet of core were recovered in 3 core runs. Mudrocks above the Glenn Sand include the marker interval used in the correlation network and definition of discrete genetic intervals. The entire Glenn Sand interval was cut, but the bottom 2 to 4 feet were not recovered in the last core run. Well site observations noted that oil was bleeding from discrete stratigraphic intervals of 1 to 6 feet thick in DGI A, C, D and E.

Work in progress includes collection and evaluation of data from the Self No. 82 we.. (vertical test well). The core is being properly archived including gamma-ray emission scanning and photography. The core is being described for variations in sedimentary textures, structures, and fabrics, as well as other relevant attributes. Subsamples are being collected for porosity, permeability, clay content, and compression and shear velocity measurements. Knowledge gained from the core will be vital to the interpretation and evaluation of the microresistivity images.

\section{Engineering Description and Simulation}

In the last report, we presented a two step procedure for constructing the reservoir description. ${ }^{1}$ The two step procedure involves first constructing the geological facies description followed by defining the petrophysical properties for individual grid blocks consistent with the presence of the appropriate facies. Subsequent to the last report, we observed that some additional data regarding the well completion and shut in were available. This resulted in modifications of the well openings and shut-ins of the existing and old wells.

We also received additional initial potential data from some of the old wells drilled before 1940. In conducting the flow simulations with the modified data, we compared the simulated initial potential data with the observed initial potential data for many of the wells. We tried 
different bottom hole pressures from 200 psia to 600 psia. We observed that 400 psia of bottom hole pressure provided the best comparison. The results are shown in Figure 3. The results for other bottom hole pressures were not significantly different from these results. Considering the uncertainties involved in how these wells were actually completed, the comparison was deemed satisfactory. Using the bottom hole pressure as 400 psia, we did the simulation of the entire Self unit. The comparison between the simulated results and the observed results is shown in the Figure 4. The results match well except at for early years. This discrepancy may be explained by the fact that: (i) the early production data are estimated based on the cumulative production data available in 1940; and (ii) during the early years, all the wells were drilled on the boundary of the unit which may have resulted in the drainage of the surrounding leases. In our simulation, we assumed that the Unit was enclosed. Overall, the results are deemed satisfactory.

Based on the simulation results and the resulting saturation profiles, the vertical test well was spudded on December 27th between wells 59, 63, 81 and 64 (See Figure 5). New data are being presently collected from the well. The results will be presented in the next report.

\section{References}

1. Quarterly Report, Integrated Approach Towards the Application of Horizontal Wells to Improve Waterflooding Performance (Contract No. DE-FC22-93BC14951), July 1 September 30, 1993. 


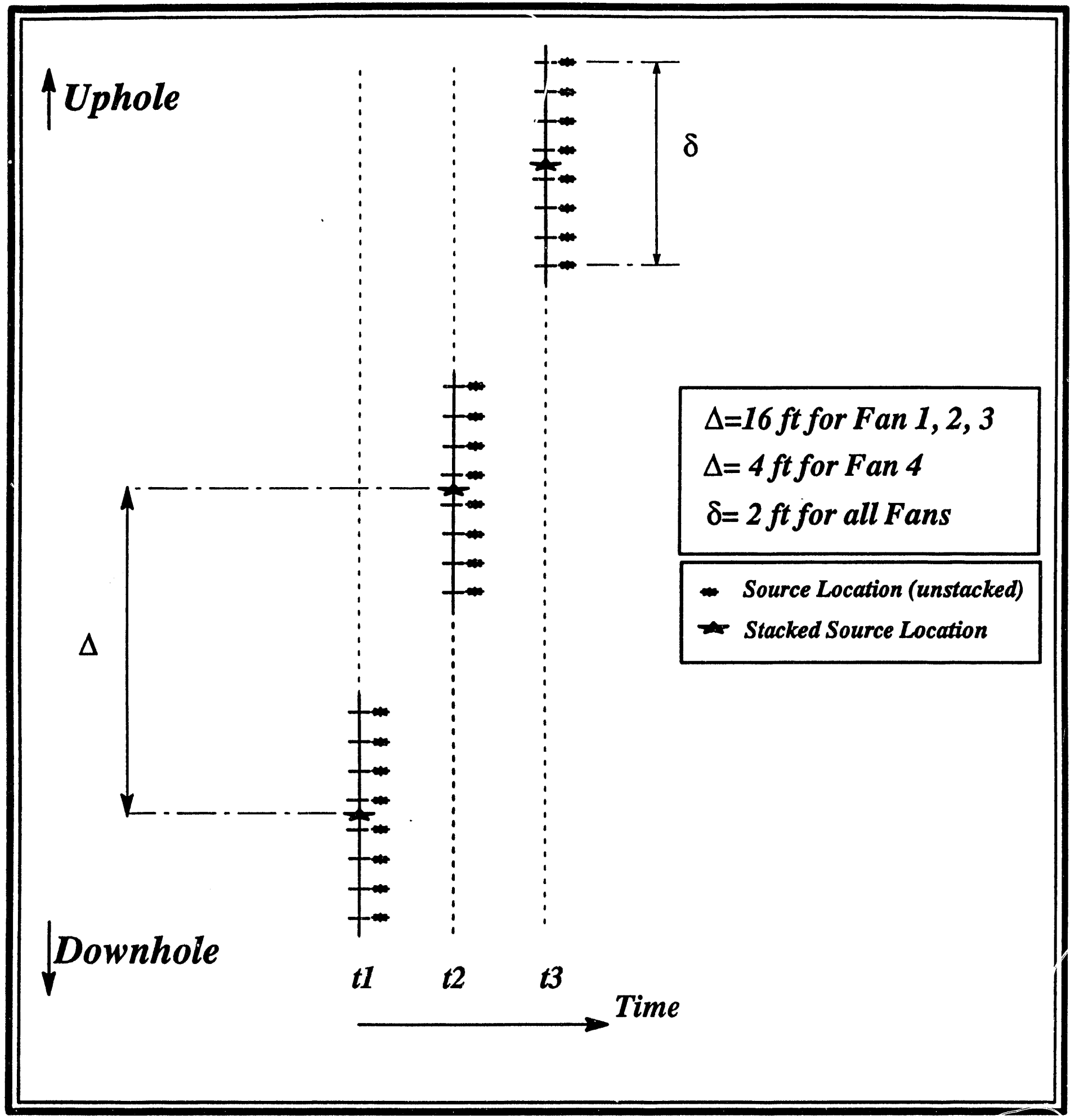

Source Locations at Three Consecutive Time Positions

Figure 1 
Well 72
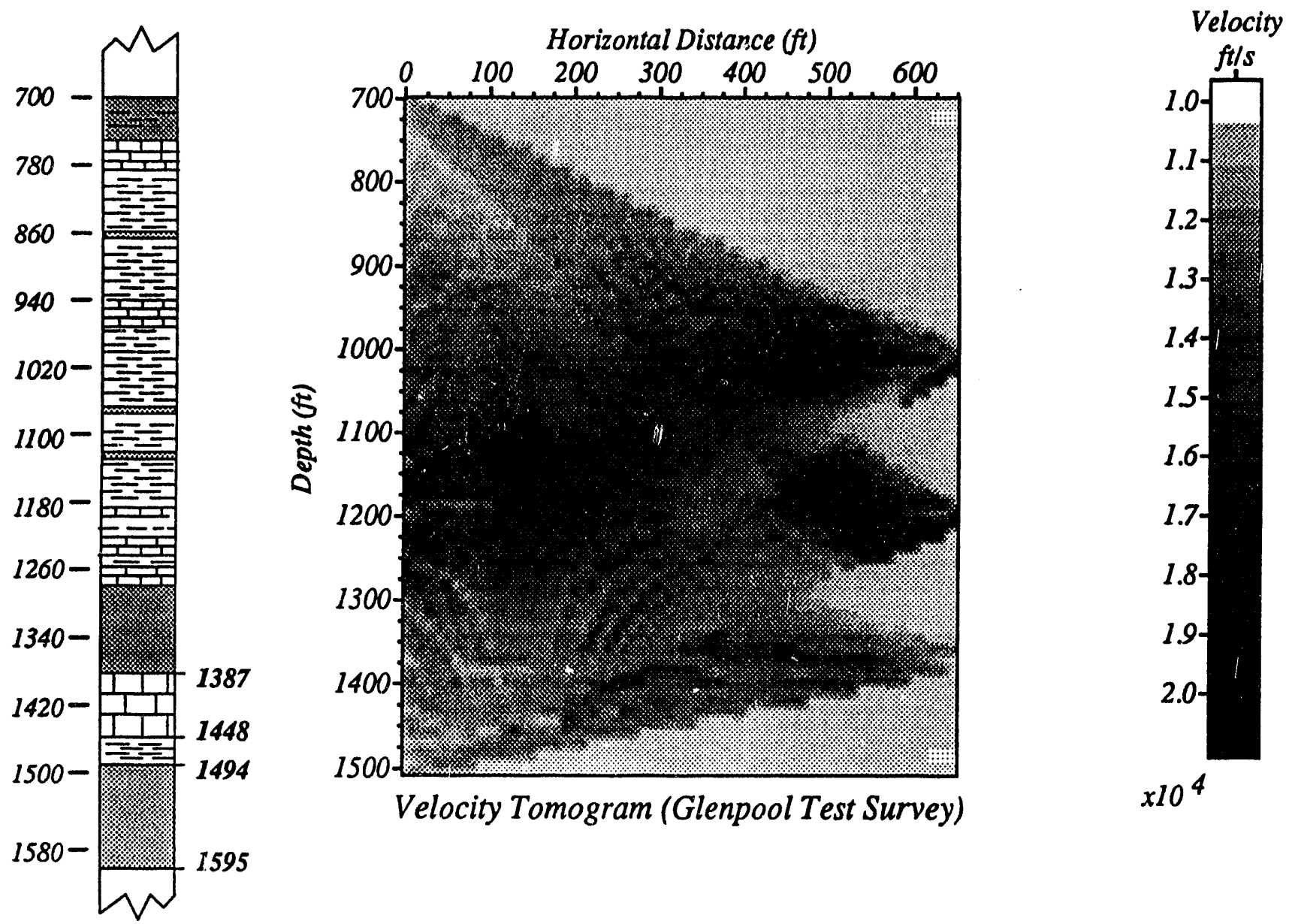

Figure 2 


\section{Simulated and Field Performance for Self Unit}

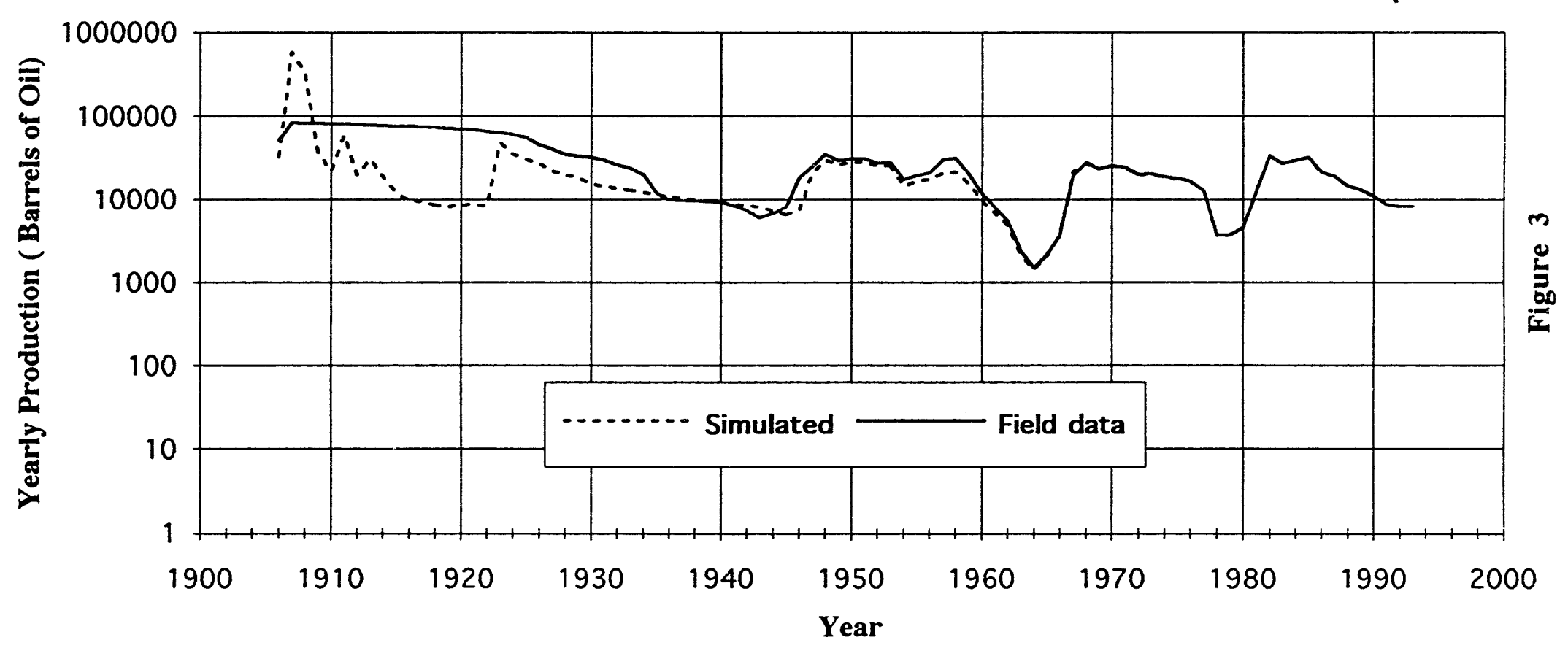




\section{Initial Potential Comparison}

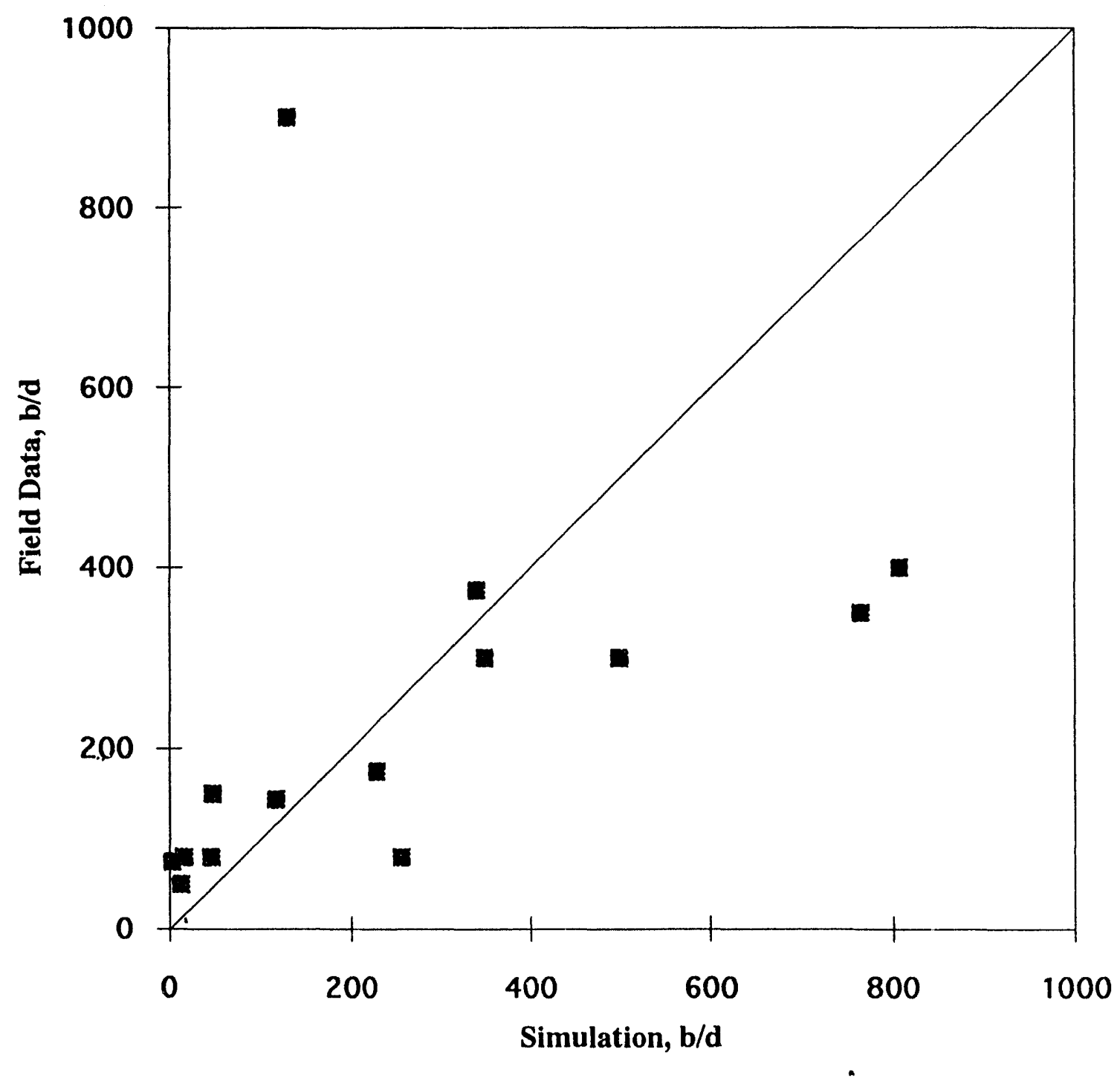

Figure 4 


\section{Well Locations}

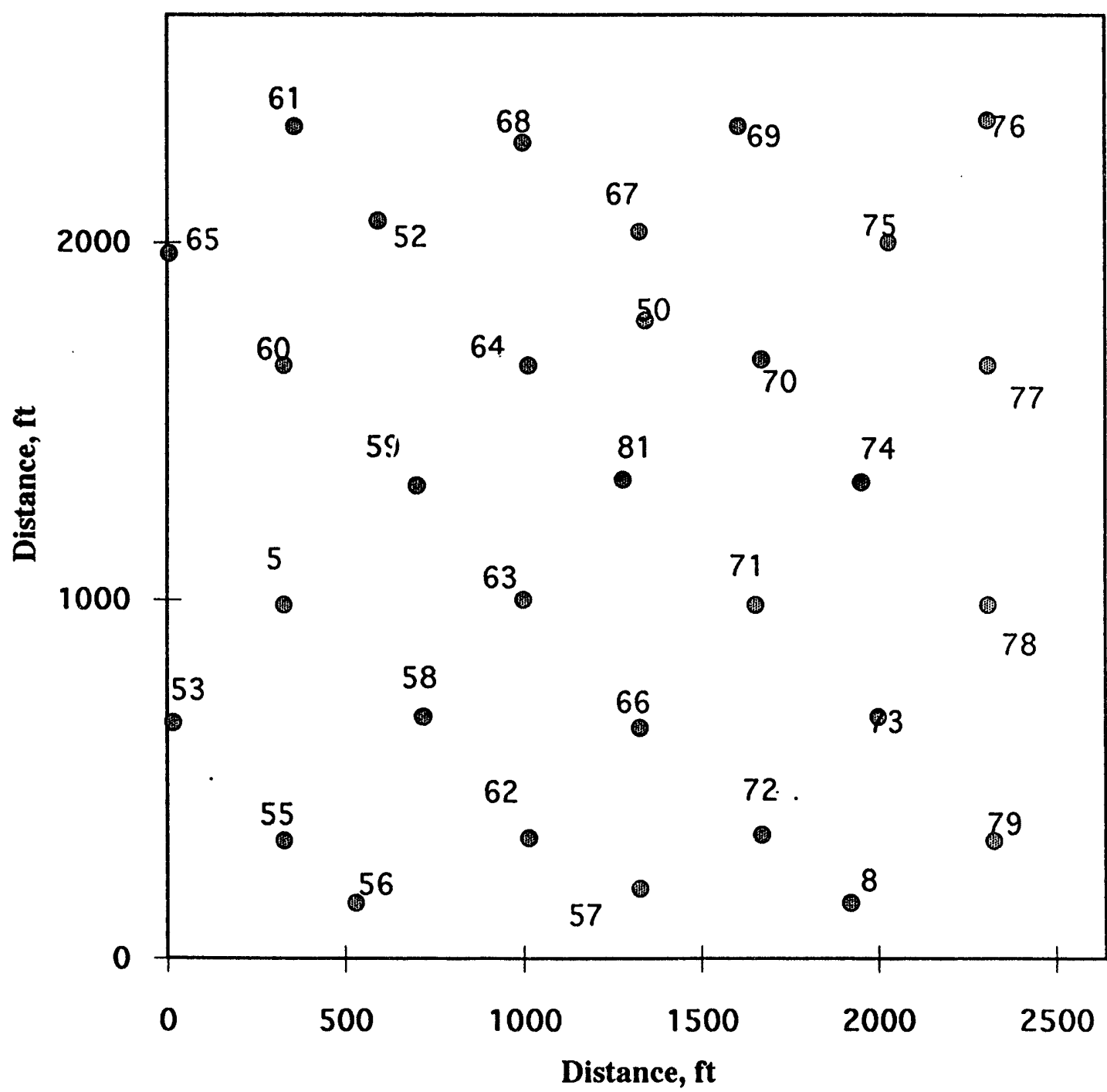

Figure 5

9 

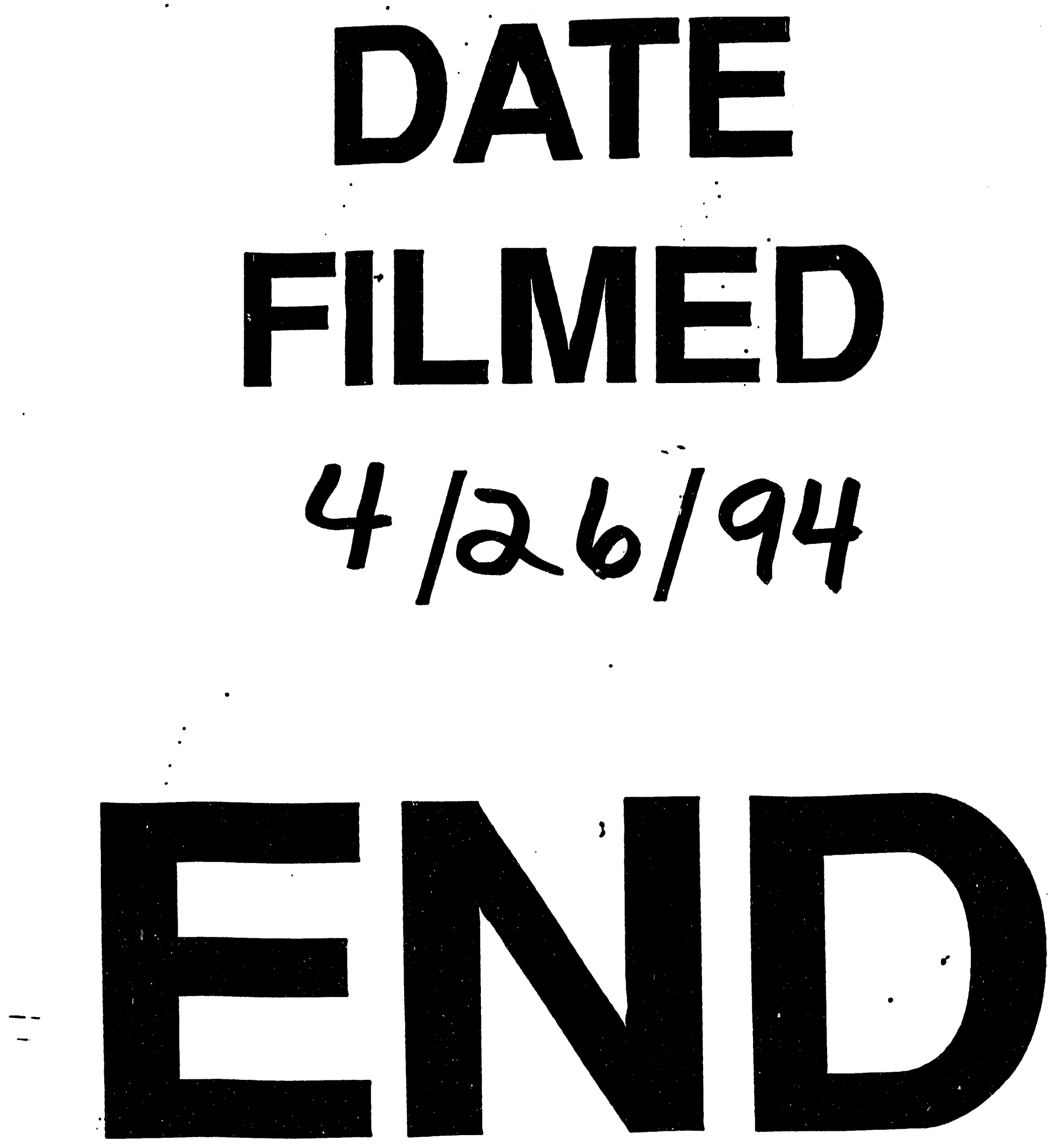
